\title{
Supporting Information: Delayed lubricant depletion of Slippery Liquid Infused Porous Surfaces using precision nanostructures
}

Sophia K. Laney, ${ }^{1 \neq}$ Martyna Michalska, ${ }^{1 \neq}$ Tao Li ${ }^{1 *}$ Francisco V. Ramirez, ${ }^{1}$ Mark Portnoi, ${ }^{1}$ Junho Oh, ${ }^{2,3}$ Iain G. Thayne, ${ }^{4}$ Ivan P. Parkin, ${ }^{5}$ Manish K. Tiwari, ${ }^{2,6^{*}}$ and Ioannis Papakonstantinou ${ }^{*}$

${ }^{1}$ Photonic Innovations Lab, Department of Electronic \& Electrical Engineering, University College London, Torrington Place, London WC1E 7JE, UK

${ }^{2}$ Nanoengineered Systems Laboratory, Department of Mechanical Engineering, University College London, Torrington Place, London WC1E 7JE, UK

${ }^{3}$ Department of Mechanical Engineering, Hanyang University, Ansan, 15588. South Korea

${ }^{4}$ James Watt School of Engineering, University of Glasgow, Glasgow G12 8LT

${ }^{5}$ Department of Chemistry, University College London, Torrington Place, London WC1E 7JE, $U K$

${ }^{6}$ Wellcome/EPSRC Centre for Interventional and Surgical Sciences (WEISS), University College London, London, W1W 7TS, UK

* These authors contributed equally

*Email: i.papakonstantinou@ucl.ac.uk; m.tiwari@ucl.ac.uk 


\section{Table of Content}

\begin{tabular}{|l|l|}
\hline Supporting Tables & Page \\
\hline Table S1 - Etching times and deposition thickness for nanostructure generation & $\mathrm{S} 2$ \\
\hline Table S2 - Oxford RIE etching conditions for $\mathrm{SiO}_{2}$ mask etching & $\mathrm{S} 2$ \\
\hline Table S3 - STS etching conditions for Si etching & $\mathrm{S} 2$ \\
\hline Table S4 - Interfacial energy values & $\mathrm{S} 3$ \\
\hline Supporting Text & \\
\hline Text S1 - Critical roughness & $\mathrm{S} 3$ \\
\hline Text S2 - Thermodynamic stability of lubricant film & $\mathrm{S} 3$ \\
\hline Text S3 - Spreading coefficient of Krytox 1525 on water & $\mathrm{S} 4$ \\
\hline References & $\mathrm{S} 4$ \\
\hline
\end{tabular}

\section{Supporting Tables}

Table S1 - Etching times and deposition thickness for nanostructure generation

\begin{tabular}{|l|l|l|l|l|l|l|}
\hline Sample & $\begin{array}{l}\mathbf{S i O}_{2} \\
\text { thickness / } \\
\text { nm }\end{array}$ & $\begin{array}{l}\mathbf{O}_{2} \text { etch } \\
/ \mathbf{s}\end{array}$ & $\begin{array}{l}\mathbf{C H F}_{3} / \mathbf{A r} \\
\mathbf{e t c h} / \mathbf{m i n}\end{array}$ & $\begin{array}{l}\mathbf{C l}_{2} \text { etch } \\
/ \mathbf{m i n}\end{array}$ & $\begin{array}{l}\boldsymbol{t} \mathbf{A L D} \\
/ \mathbf{n m}\end{array}$ & $\begin{array}{l}\mathbf{C l}_{2} \text { etch } \\
/ \text { min }\end{array}$ \\
\hline Nanoholes & 200 & 5 & 9 & 10 & N/A & N/A \\
\hline Nanopillars & 200 & 5 & 6 & 10 & N/A & N/A \\
\hline Nanotubes & 200 & 5 & 9 & 5 & 30 & 10 \\
\hline
\end{tabular}

Table S2 - Oxford RIE etching conditions for $\mathrm{SiO}_{2}$ mask etching

\begin{tabular}{|l|l|l|l|l|}
\hline \multicolumn{5}{|c|}{ Oxford RIE conditions - capacitively coupled plasma } \\
\hline \multirow{2}{*}{$\begin{array}{l}\text { Oxygen } \\
\text { breakthrough }\end{array}$} & Pressure / mTorr & RF Power / W & $\mathbf{O}_{\mathbf{2}} /$ sccm \\
\cline { 2 - 6 } & 50 & 100 & 50 & \\
\hline \multirow{2}{*}{$\mathbf{S i O}_{2}$ etch } & Pressure /mTorr & $\mathbf{R F}$ Power / W & $\mathbf{C H F}_{3} / \mathbf{s c c m}$ & $\mathbf{A r} / \mathbf{s c c m}$ \\
\cline { 2 - 6 } & 50 & 200 & 12 & 38 \\
\hline
\end{tabular}

Table S3 - STS etching conditions for Si etching

\begin{tabular}{|c|c|c|c|c|c|c|c|c|}
\hline \multicolumn{9}{|c|}{ ASE, STS MESC Multiplex conditions - inductively coupled plasma } \\
\hline \multirow[t]{2}{*}{ Sample } & \multicolumn{4}{|c|}{$1^{\text {st }} \mathrm{Si}$ etch } & \multicolumn{4}{|c|}{$2^{\text {nd }}$ Si etch } \\
\hline & $\begin{array}{l}\text { Coil } \\
\text { /W }\end{array}$ & $\begin{array}{l}\text { Platen } \\
\text { /W }\end{array}$ & $\begin{array}{l}\mathrm{P} \\
\text { /mTorr }\end{array}$ & $\begin{array}{l}\mathrm{t} \\
/ \mathrm{min}\end{array}$ & $\begin{array}{l}\text { Coil } \\
\text { /W }\end{array}$ & $\begin{array}{l}\text { Platen } \\
\text { /W }\end{array}$ & $\begin{array}{l}\mathrm{P} \\
\text { /mTorr }\end{array}$ & $\begin{array}{l}\mathrm{t} \\
/ \mathrm{min}\end{array}$ \\
\hline Nanoholes & 300 & 40 & 3 & 10 & N/A & N/A & N/A & N/A \\
\hline Nanopillars & 300 & 100 & 3 & 10 & $\mathrm{~N} / \mathrm{A}$ & $\mathrm{N} / \mathrm{A}$ & $\mathrm{N} / \mathrm{A}$ & $\mathrm{N} / \mathrm{A}$ \\
\hline Nanotubes & 500 & 200 & 3 & 5 & 300 & 100 & 3 & 10 \\
\hline
\end{tabular}


Table S4 - Interfacial energy values

\begin{tabular}{|l|l|}
\hline & Surface tension $/ \mathbf{~ m N} / \mathbf{m}$ \\
\hline (Krytox 1525) $^{1} \gamma_{L}$ & 19 \\
\hline${\text { (DI water) } \gamma_{W}}_{\text {Krytox-Water } \gamma_{L W}}^{1}$ & 72.2 \\
\hline
\end{tabular}

\section{Supporting Text}

\section{Text S1 - Critical roughness}

Based on the surface energy balance, there is a minimum surface roughness required for a thermodynamically stable configuration which is predicted by: ${ }^{2}$

$$
R>\frac{\gamma_{L W}}{\gamma_{L} \cos \theta_{L}-\gamma_{W} \cos \theta_{W}}
$$

For the case of a water droplet and Krytox 1525, the threshold value to support a stable SLIPS is $R>1.2$.

\section{Text S2 - Thermodynamic stability of lubricant film}

The stability of a lubricant film under static conditions can be assessed by considering the interfacial energy of the solid that is fully wetted either by water $\left(E_{W}\right)$ - the only immiscible liquid tested in this paper, or the lubricant with $\left(E_{L W}\right)$ or without $\left(E_{L}\right)$ a water droplet atop of the lubricant: ${ }^{2}$

1. Lubricant wets the solid with water present

$$
E_{L W}=R \gamma_{S L}+\gamma_{L W}+\gamma_{W}
$$

2. Lubricant wets the solid without water present

$$
E_{L}=R \gamma_{S L}+\gamma_{L}
$$

3. Water wets the solid

$$
E_{W}=R \gamma_{S W}+\gamma_{W}
$$

where $\mathrm{R}$ is the roughness ratio and $\gamma_{S L}, \gamma_{L W}, \gamma_{L}$ and $\gamma_{W}$ represent the surface energies of the solid-lubricant interface, lubricant-water interface, lubricant-air and water-air interface, respectively. 
To ensure water does not wet the solid, $E_{W}$ must be in a higher energy state than $E_{L W}$, we therefore write $E_{W}-E_{L W}>0$, which further expands to:

$$
R\left(\gamma_{S W}-\gamma_{S L}\right)-\gamma_{L W}>0
$$

To reduce this to measurable quantities, we can use Young's equation to obtain

$$
R\left[\left(\gamma_{S}-\gamma_{W} \cos \theta_{W}\right)-\left(\gamma_{S}-\gamma_{L} \cos \theta_{L}\right)\right]-\gamma_{L W}>0
$$

which can be simplified to:

$$
\Delta E_{L W}=R\left(\gamma_{L} \cos \theta_{L}-\gamma_{W} \cos \theta_{W}\right)-\gamma_{L W}>0
$$

The same approach is taken for $\Delta E_{L}$ to obtain:

$$
\Delta E_{L}=R\left(\gamma_{L} \cos \theta_{L}-\gamma_{W} \cos \theta_{W}\right)-\gamma_{W}-\gamma_{L}>0
$$

where $\theta_{L}$ and $\theta_{W}$ are the Young's contact angles of the lubricant and water on the solid surface.

\section{Text S3 - Spreading coefficient of Krytox 1525 on water}

Krytox is commonly used in SLIPS surfaces, by virtue of its immiscibility with water. However, to determine whether it is energetically favourable for Krytox to spread on water, the spreading coefficient is calculated by the following equation:

$$
S_{L W}=\gamma_{W}-\left(\gamma_{L}+\gamma_{W L}\right)
$$

Based on the values in Table S4, $S_{L W}$ is calculated to be 2.704 , indicating it is energetically favourable to spread on water, thus giving rise to cloaking. The ramifications of cloaking are discussed elsewhere, ${ }^{1}$ however as the aim is to compare the effect of nanostructure on performance rather than lubricant, it is not considered pertinent.

\section{References}

(1) Sett, S.; Yan, X.; Barac, G.; Bolton, L. W.; Miljkovic, N. Lubricant-Infused Surfaces for Low-Surface-Tension Fluids: Promise versus Reality. ACS Appl. Mater. Interfaces 2017, 9 (41), 36400-36408.

(2) Wong, T.-S. S.; Kang, S. H.; Tang, S. K. Y. Y.; Smythe, E. J.; Hatton, B. D.; Grinthal, A.; Aizenberg, J. Bioinspired Self-Repairing Slippery Surfaces with Pressure-Stable Omniphobicity. Nature 2011, 477 (7365), 443-447. 
